OPEN ACCESS

Edited by:

Lik-ho Tam

Beihang University, China

Reviewed by:

Yunchao Tang,

Zhongkai University of Agriculture and

Engineering, China

Yun Gao,

Southeast University, China

Bartosz Zegardlo,

University of Natural Sciences and

Humanities of Siedlce, Poland

*Correspondence:

Gao Debin

2725587643@qq.com

Specialty section:

This article was submitted to

Structural Materials,

a section of the journal

Frontiers in Materials

Received: 15 June 2021 Accepted: 09 August 2021 Published: 19 August 2021

Citation:

Xuetong $M$ and Debin G (2021) Experimental Study of Compressive Properties and Environmental Impact

of Recycled Aggregate.

Front. Mater. 8:725493.

doi: 10.3389/fmats.2021.725493

\section{Experimental Study of Compressive Properties and Environmental Impact of Recycled Aggregate}

\author{
Ma Xuetong ${ }^{1,2}$ and Gao Debin ${ }^{1,2 *}$ \\ ${ }^{1}$ School of Geological Engineering and Surveying, Chang'an University, Xi'an, China, ${ }^{2}$ Water Cycle and Geological Environment \\ Observation and Research Station for the Chinese Loess Plateau, Ministry of Education, Gansu, China
}

As the main component of fiber-reinforced recycled aggregate concrete, the properties of recycled aggregate determine whether recycled aggregate concrete can be used in engineering applications. To study the compressive properties and environmental impact of recycled aggregate, large-scale indoor compression tests were carried out on recycled aggregate under different moisture contents, concrete aggregate ratios, drywet cycles, and loads. The results showed that the crushing rate and settlement first increased and then decreased upon increasing the moisture content. Upon increasing the concrete aggregate ratio, the settlement continuously decreased, and the crushing rate decreased from 157.2 to $82.5 \%$. Upon increasing the number of dry-wet cycles, the settlement continued to increase to an upper limit of about $17.5 \%$, and the crushing rate increased to $35 \%$. Upon increasing the load, the settlement and crushing rate of the aggregate increased. These results show that the effects of aggregate ratio, moisture content, and dry-wet cycles on settlement were caused by crushing the aggregate. Based on this, a formula was constructed to predict the final settlement of reclaimed aggregate. The leaching amount of $\mathrm{Cr}$ in recycled aggregate was $0.0175-0.0375 \mathrm{mg} / \mathrm{L}$ under normal conditions, but under extreme conditions, the leaching amount of some sampling points was greater than in the standard requirements. This means that recycled aggregate may pose environmental risks that should be mitigated during use. Recycled aggregate can be used to construct sponge city storage and reuse facilities, as well as fiber-reinforced recycled aggregate concrete, but its sources need to be determined to ensure that it does not pose environmental risks.

\section{Keywords: recycled aggregate, compression test, leaching test, prediction formula, sponge city}

\section{INTRODUCTION}

Infrastructure construction consumes natural resources and generates a great deal of waste, which may lead to serious environmental and economic problems (Bendixen et al., 2019). In 2018, China produced 1.704 billion tons of construction waste, which accounted for approximately $35.9 \%$ of all solid waste. Although construction waste can be processed into recycled aggregate, its reuse rate in China is less than $10 \%$. Recycled aggregate is widely used in fiber-reinforced recycled aggregate concrete. Highly permeable water storage structures are the main features of sponge cities (Kong et al., 2020), and such structures are built using natural materials and fiber-reinforced composite materials. However, such structures are prone to 
TABLE 1 | Grading of the recycled aggregate.

\begin{tabular}{|c|c|c|c|c|c|c|c|c|}
\hline Particle size (mm) & 37.5 & 31.5 & 26.5 & 19.0 & 16.0 & 13.2 & 9.5 & 4.75 \\
\hline Accumulative remainder (\%) & 100 & 80.62 & 63.25 & 50.00 & 25.00 & 12.55 & 6.32 & 0 \\
\hline
\end{tabular}

TABLE 2 | Performance indicators of the recycled aggregate.

Particle size (mm)

4.75-37.5

Porosity (\%)

Apparent density $(\mathrm{kg} / \mathrm{m} 3)$

Bulk density $(\mathrm{kg} / \mathrm{m} 3)$

Water absorption (\%)

Optimum moisture content (\%)

Crushing value (\%)
41.3

2,105

1,235

15.6

11.6

22.7 damage due to their poor construction quality. Researchers have shown that the mechanical properties of recycled aggregate are affected by its source (Yang and Lee, 2017a; Yang and Lee, 2017b), and the physical properties of recycled aggregate are worse than those of natural aggregate (Hansen, 1992; Limbachiya et al., 2000; López-Gayarre et al., 2009; Ma et al., 2019) The water absorption rate of recycled aggregate is generally higher, but its abrasion resistance is worse than that of natural aggregate (Lee et al., 2012; Ma et al., 2019). The unit price per ton of recycled aggregate is about $40 \%$ lower than that of natural aggregate. The use of recycled aggregate to build water storage structures can reduce the consumption of natural materials and provide a new method for the application of recycled aggregate (Yuan et al., 2018; Chen et al., 2020; Shen et al., 2020). Material settlement and environmental pollution may occur when recycled aggregate is used for water storage structures. Therefore, it is necessary to study the material settlement characteristics and pollution of construction waste in water storage structures (Saeed, 2008).

Many scholars have investigated the mechanical properties and the potential reusability of recycled aggregate in concrete and roadbeds (Yt et al., 2020; Tang et al., 2021a; Tang et al., 2021b). Most studies have focused on the wear value and gradation of recycled aggregate, particularly fine aggregate $(>5 \mathrm{~mm}$ ) (Chen, 2004; Hong, 2016; Chang, 2017; Yang et al., 2017); However, a high porosity is needed when recycled aggregate is used in sponge cities, but few studies have focused on this. Recycled aggregate may also pose certain environmental risks that can affect human health. Galvin et al. (2012) analyzed the residues of two recycling facilities in Spain. Meza et al. analyzed the contamination of crushed concrete and brick resulting from the demolition of a university building in the United States (Lopez Meza et al., 2008; López; Meza et al., 2009). Li et al. (2020) analyzed the influence of the construction waste sample ratio, liquid-solid ratio, $\mathrm{pH}$, and other factors on the leaching of heavy metals. Recycled aggregate can absorb certain pollutants in rainwater (Wang et al., 2015). Coarse aggregate may undergo ion exchange when kept in water for a long time, making it necessary to study its mechanical properties and leaching properties under these conditions.

In this paper, the mechanical properties and pollution of recycled aggregate were studied, and a formula was established to predict the settlement of recycled aggregate to guide the use of recycled aggregate for the construction of sponge city water storage structures. The following sections of this study are structured as: Materials and Methods describes the methodology of the research; Result presents the results of the research; Conclusion concludes this study.

\section{MATERIALS AND METHODS}

\section{Materials}

The recycled aggregate used in this study was taken from Xi'an, and its main components were concrete and bricks. The recycled aggregate was mainly obtained from the demolition of old buildings, and it was crushed by a machine. Its initial mix ratio was 5:5 (mass ratio of concrete to brick aggregate). Table 1 provides the gradation of the mixed aggregate, and Table 2 provides the performance indicators of the recycled aggregate.

\section{Methods}

\section{Consolidation Experiment}

Three different samples were designed for consolidation tests:

(1) Aggregate with different moisture contents: Control the mixing ratio at 5:5 and change the moisture content of the aggregate at $6,9,12$, and $15 \%$. Recycled aggregate with different moisture contents was obtained by adding water to dry aggregate, and then recycled aggregate was sealed for $18 \mathrm{~h}$ to make the moisture more uniform. We calculated the mass of water to be added according to the mass of dry recycled aggregate.

(2) Aggregate with different ratios: The proportion of concrete in the mixed aggregate was $0,20,40,60,80$, and $100 \%$.

(3) Aggregate with different numbers of dry-wet cycles: The number of dry-wet cycles was $0,5,10,15$, and 20. The recycled aggregate was immersed in water until the aggregate was saturated. Then, it was removed and put into a drying oven for $18 \mathrm{~h}$ to reduce its moisture content to $0 \%$ as much as possible. This process is constituted one dry-wet cycle. The scheme of the test is shown in Table 3.

The experiment used a WAW-1000 electro-hydraulic servo universal testing machine. The diameter of the specimen tube was $500 \mathrm{~mm}$, and its height was $250 \mathrm{~mm}$. The specimens were first loaded into a experimental facility, and the loading levels were $250,500,750,1,000,1,250$, and 1,500 kPa. Percentage 
TABLE 3 | The scheme of the consolidation test.

\begin{tabular}{lccc}
\hline $\begin{array}{l}\text { Serial } \\
\text { number }\end{array}$ & $\begin{array}{c}\text { Number } \\
\text { of dry-wet } \\
\text { cycles }\end{array}$ & $\begin{array}{c}\text { The proportion of } \\
\text { concrete (\%) }\end{array}$ & $\begin{array}{c}\text { The moisture } \\
\text { content w (\%) }\end{array}$ \\
\hline$A_{1}$ & 0 & 50 & 6 \\
$A_{2}$ & & & 9 \\
$A_{3}$ & & 0 & 12 \\
$A_{4}$ & & 20 & 15 \\
$B_{1}$ & & 40 & \\
$B_{2}$ & & 60 & \\
$B_{3}$ & & 80 & \\
$B_{4}$ & & 100 & \\
$B_{5}$ & 0 & 50 & \\
$B_{6}$ & 5 & & \\
$C_{1}$ & 10 & & \\
$C_{2}$ & 15 & & \\
$C_{3}$ & 20 & & \\
$C_{4}$ & 5 & & \\
$C_{5}$ & & & \\
\hline
\end{tabular}

readings were recorded every $5,10,15$, and $30 \mathrm{~min}$ for each loading level (CN-GB, 2019). When the settlement was stable, the next loading level was carried out. After the experiment, the sample was dried and sieved, and the mass of each particle size fraction was obtained. The particle fragmentation value was calculated (Kong et al., 2017). Particle fragmentation indicates that the material broke into smaller particles under a load, which caused particle-level recombination and

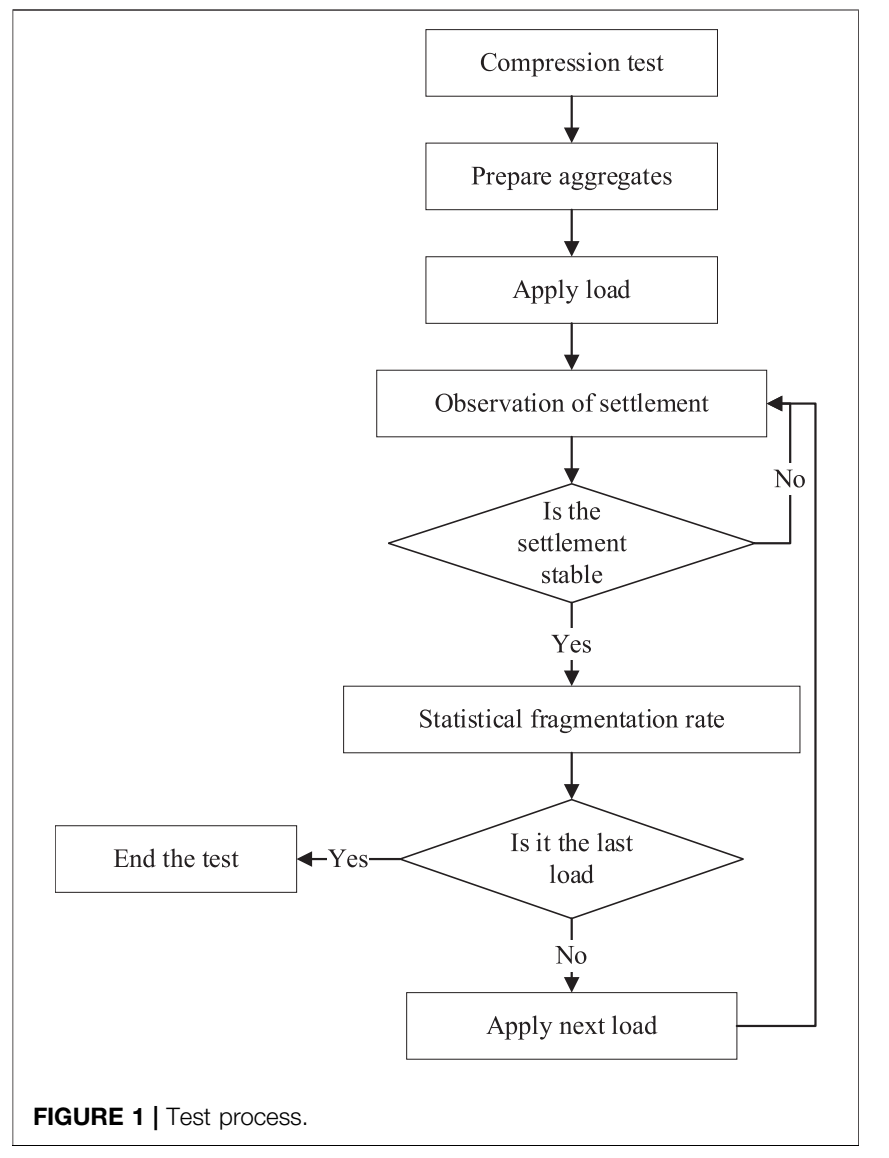

affected the properties of materials. It can be calculated by Equation 1.

$$
B_{g}=\sum_{1}^{n}\left|P_{i 0}-P_{i 1}\right|
$$

where $n$ is the grade of the material, $\% ; P_{\mathrm{i} 0}$ is the proportion of the particle size before compression, $\% ; P_{\mathrm{i} 1}$ is the proportion of the particle size after compression, $\%$.

The test process is shown in Figure 1.

\section{Environmental Impact Experiment}

The environmental risk of recycled aggregate was experimentally studied in this paper using the following scheme.

The diffusion solution used in the experiment was a mixed solution of concentrated sulfuric acid and concentrated nitric acid, with a mass ratio of 2:1. Two different gradient diffusion solutions with $\mathrm{pH} 5.0$ and 7.0 were configured (concentrated sulfuric acid and concentrated nitric acid were purchased from Sinopharm Group, both of analytical grade). The recycled aggregate used in the experiment was taken from three sampling sites: Xi'an tap water district, Xiying Road, and Xinghuo Railway.

The leaching experiment followed ASTM C1308-08 and EANEN7371. The enhanced leaching test involved monitoring the $\mathrm{pH}$ of the solution during the test, and the $\mathrm{pH}$ was corrected in time to ensure it was constant during the test; however, in the standard leaching test, the $\mathrm{pH}$ was not controlled, and it changed over time. In the experiment, the ratio of the volume of the diffusion leaching solution to the surface area of the recycled aggregate was set to $10: 1\left(\mathrm{ml} / \mathrm{cm}^{2}\right)$. The concentration of heavy metal pollutants was determined by atomic absorption spectrophotometry, and the $\mathrm{pH}$ of the diffusion solution was measured by a $\mathrm{pH}$ meter. The test steps are as follows:

(1) The prepared diffusion leaching solution was injected into a $2 \mathrm{~L}$ beaker.

(2) The recycled aggregate was wrapped by a nylon polyethylene fishing line and transferred to the beaker. This allowed the recycled aggregate to be completely immersed in the diffusion solution, and the bottom was about $5 \mathrm{~cm}$ from the bottom of the beaker. After $2 \mathrm{~h}$, the recycled aggregate was removed from the diffusion leaching solution to analyze the concentration of heavy metals in the beaker solution.

(3) The recycled aggregate was placed in another beaker containing the same diffusion extraction solution, and it was removed after $5 \mathrm{~h}$ to determine the concentration of heavy metals in the solution.

(4) The recycled aggregate was placed in another beaker containing the same diffusion extraction solution and then removed after $17 \mathrm{~h}$ to determine the concentration of heavy metals in the solution.

(5) The recycled aggregate was placed in another beaker containing the same extraction solution and removed after $24 \mathrm{~h}$ to determine the concentration of heavy metals in the solution.

(6) Step 5 was repeated until heavy metal ions could not be detected in the solution. 


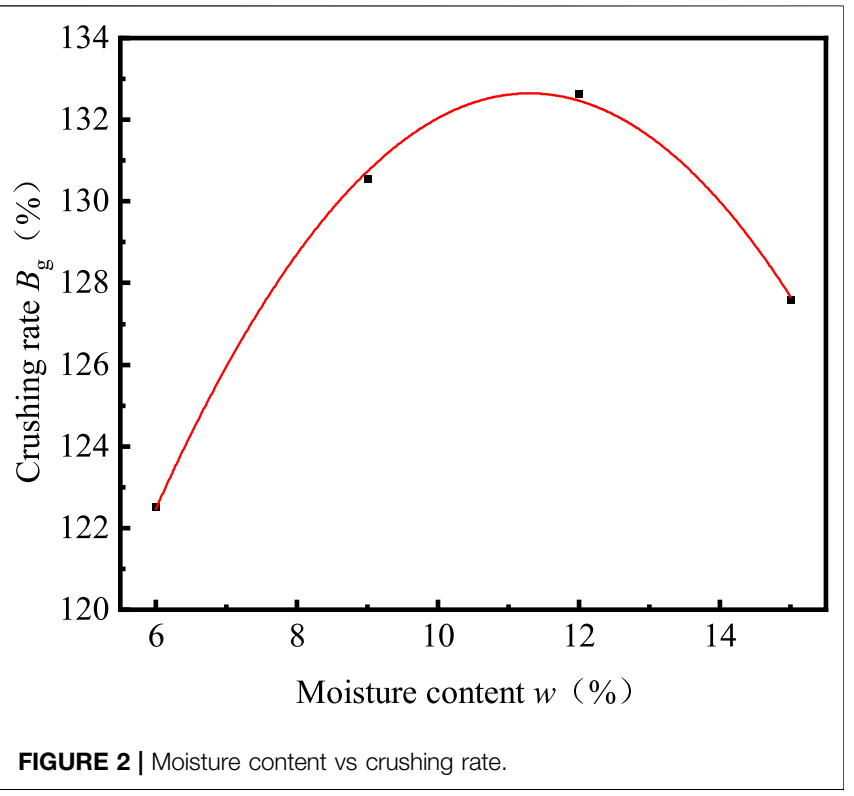

After the experiment, the cumulative mass of pollutants diffused from recycled aggregate was calculated by Equation 3.

$$
\mathrm{A}_{\max }=\sum C_{i} \times V_{L, i}
$$

where $A_{\max }$ is the mass of accumulated pollutants, mg; $C_{\mathrm{i}}$ is the concentration of pollutants in the $i$ th diffusion solution, $\mathrm{mg} / \mathrm{L}$; $V_{L, i}$ is the volume of the diffusion solution, $\mathrm{L}$.

\section{RESULTS}

\section{Crushing Characteristics of Recycled Aggregate Effect of Moisture Content on the Crushing Rate}

As shown in Figure 2, the crushing rate first increased and then decreased upon increasing the moisture content. When the moisture content increased from 6 to $12 \%$, the crushing rate increased from 122.52 to $132.64 \%$. When the moisture content increased from 12 to $15 \%$, the crushing rate decreased from 132.64 to $127.60 \%$. The relationship between the moisture content and the crushing rate was established as:

$$
B_{g}=-0.37 w^{2}+8.21 w+86.298, R^{2}=0.99
$$

where $w$ is the moisture content of recycled aggregate, $\% ; B_{\mathrm{g}}$ is the absolute value of recycled aggregate, $\%$.

As shown in Equation 3, the crushing rate reached the maximum when the moisture content of the aggregate was $11.09 \%$, which is close to the optimal moisture content of the recycled aggregate. This may indicate that when the moisture content was low, water mainly existed in the particle interior, which softened the particles and increased the particle breakage rate at higher moisture contents. When the moisture content exceeded the optimal value, water mainly acted as a lubricant, so the particle breakage rate decreased upon increasing the moisture content. Changes in the crushing rate of recycled aggregate with water content were the same as changes in the maximum dry density of gravel soil with water content (Nakaoka et al., 1994).

Effect of Aggregate Proportion on the Crushing Rate As shown in Figure 3, upon increasing the proportion of concrete, the crushing rate decreased gradually. When the concrete aggregate increased from 0 to $100 \%$, the crushing rate decreased from 157.2 to $82.5 \%$, which shows that increasing the proportion of concrete linearly decreased the crushing rate. This means that the strength of concrete aggregate was much greater than that of brick aggregate; therefore, the strength of a structure can be improved by increasing the proportion of concrete aggregate.

\section{Effect of the Dry-Wet Cycle on the Crushing Rate} As shown in Figure 4, the number of dry-wet cycles had a nonlinear relationship with the crushing rate. Upon increasing the number of dry-wet cycles, the crushing rate decreased continuously, which means that the particle crushing eventually stabilized. The dry-wet cycles may have destroyed the particle structure, which increased the crushing rate. This also indicates that there is a certain limit for particle crushing under certain conditions (Hardin, 1985; Einav, 2007), and the crushing rate may increase by about $35 \%$.

\section{Settling Characteristics of Recycled Aggregate Effect of Moisture Content on Settlement}

As shown in Figure 5, upon increasing the water content, the settlement under the same load increased first and then decreased. The variation in the settlement with moisture content was consistent with that of the crushing rate with water content, indicating that the moisture content affected the settlement of recycled aggregate by affecting the crushing rate.

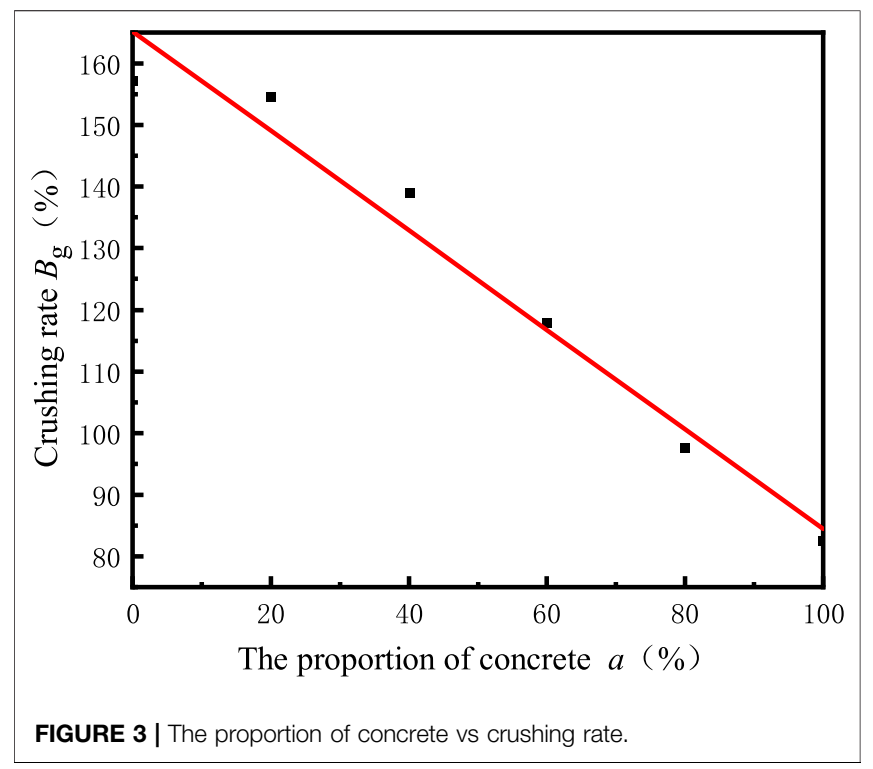



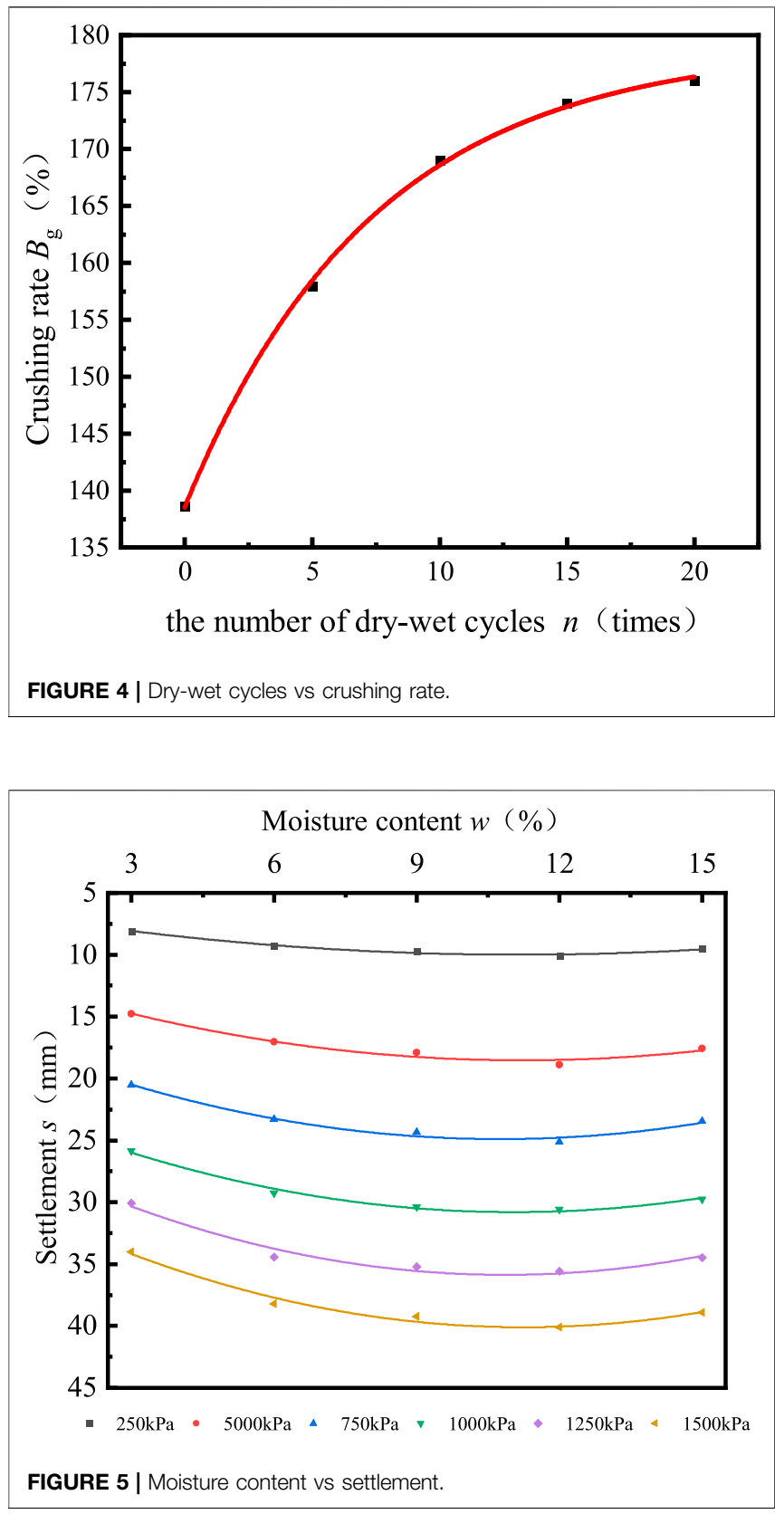

\section{Effect of Aggregate Proportion on Settlement}

Figure 6 shows the relationship between concrete aggregate proportion and compressive settlement under different loads. Upon increasing the proportion of concrete aggregate, the settlement of aggregate decreased, which is consistent with the aggregate crushing trend; therefore, the aggregate proportion also affects the compression settlement by affecting the aggregate crushing rate.

\section{Effect of the Dry-Wet Cycles on Settlement}

Figure 7 shows the relationship between the number of dry-wet cycles and settlement under different loads. Upon increasing the number of dry-wet cycles, the settlement gradually increased, but the slope of the curve decreased. That is, the compressive
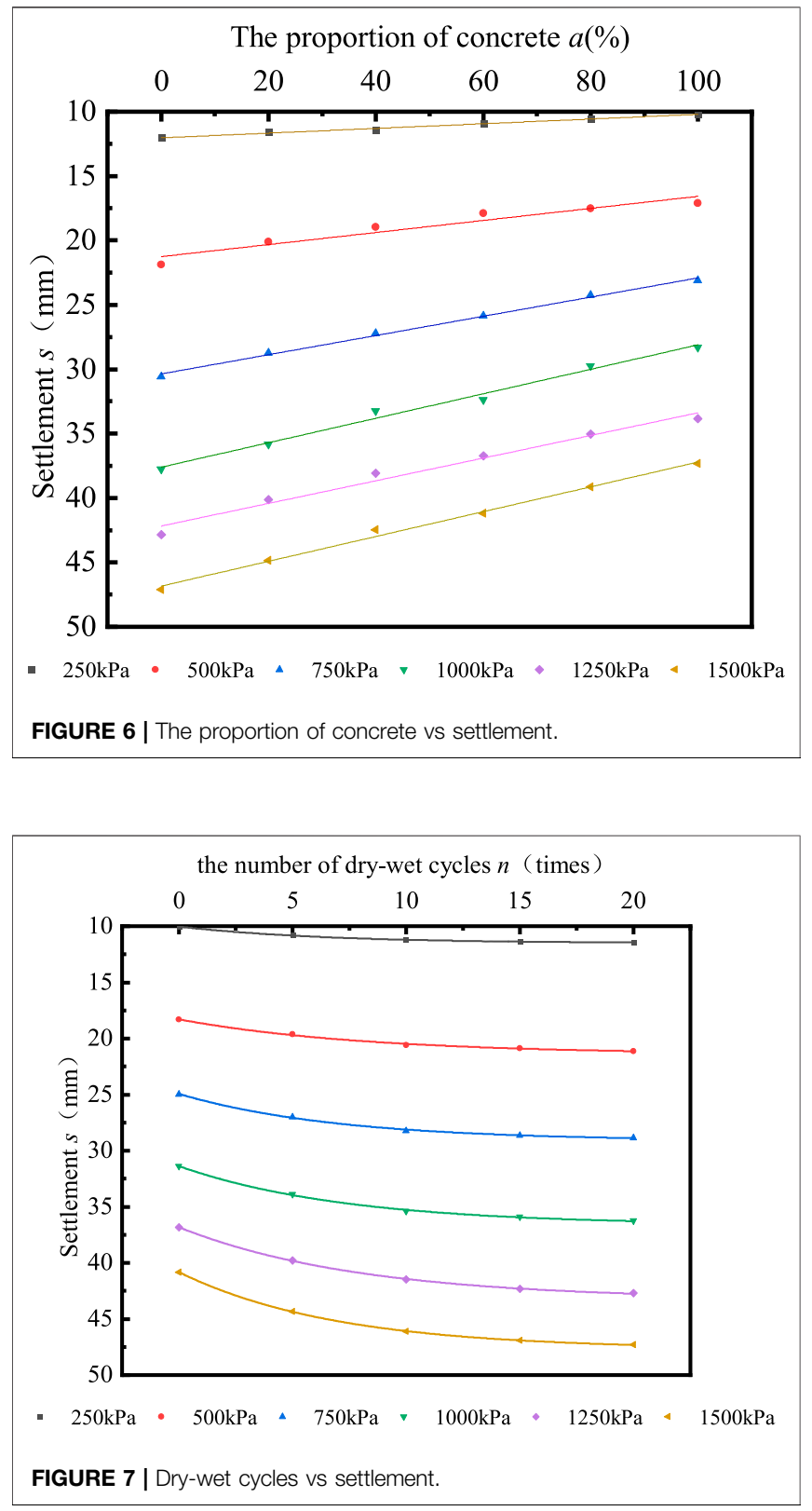

settlement of recycled aggregate under long-term dry-wet cycles may have an upper limit, which is about 14.9-17.5\%.

\section{Establishment of the Settlement Prediction Formula}

In applications, layered backfill is the most commonly used structural filling method. Settlement prediction is mainly carried out via post-construction monitoring. If settlement can be controlled during backfilling, the workload of postconstruction settlement observation may be reduced, which can help ensure construction quality.

Based on a large number of indoor test results, we tried to establish a predictive relationship between the settlement of recycled aggregate filler and aggregate moisture content, proportion, dry-wet cycles, and 


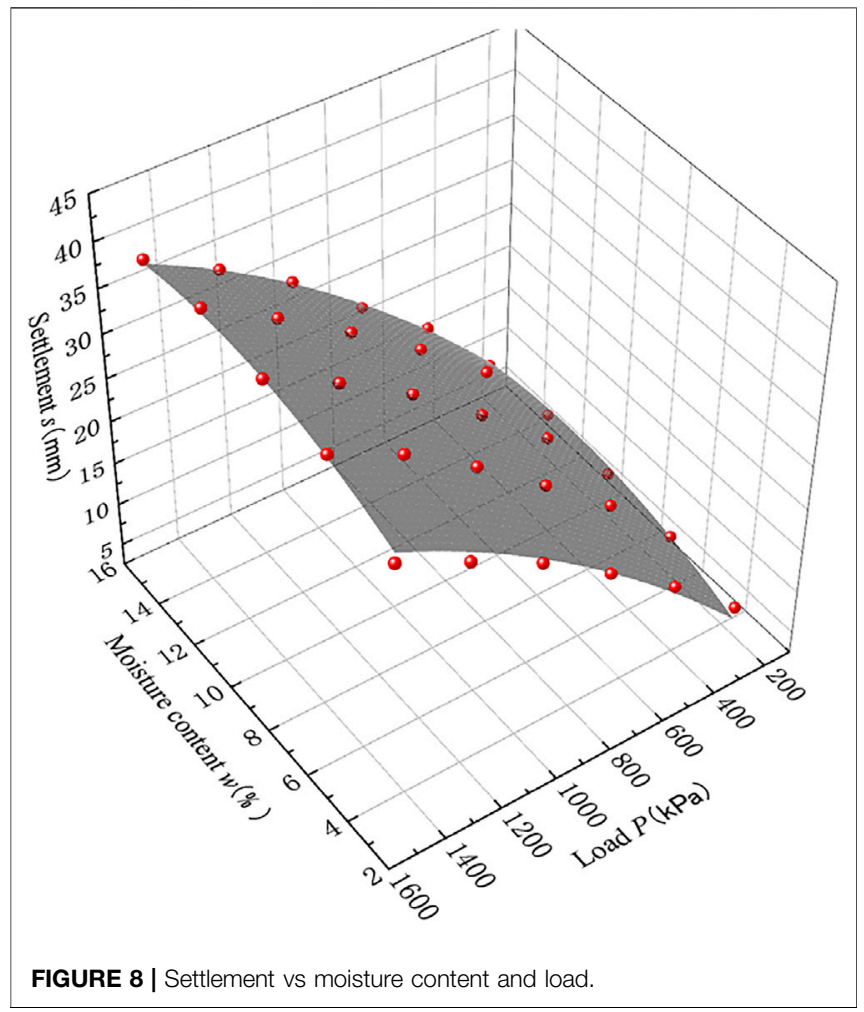

load. As shown in Figure 8, there is a good relationship between settlement, moisture content, and load.

First, according to the relationship curves of settlement and loads under different moisture contents, the formula describing the relationship between moisture content, load, and settlement of mixed aggregate was established as follows:

$$
s=-0.068 w^{2}+1.501 w+0.035 P-5.559, R^{2}=0.99
$$

where $w$ is the moisture content of recycled aggregate, $\%$; $p$ is the load on the recycled aggregate, $\mathrm{kPa}$; $s$ is the settlement of recycled aggregate, $\mathrm{mm}$.

To reduce the number of equation parameters, the compression settlement of 5:5 recycled aggregate (mass ratio of concrete to brick aggregate is 5:5) was taken as the benchmark, and the equation was established according to this proportion to describe the compression settlement of aggregate with different compositions. For this reason, the parameter $K$ was introduced as a coefficient of the settlement ratio. Then, the relationship between the aggregate proportion, load, and $K$ was obtained (Figure 9).

Similarly, the formula to predict the compressive settlement of recycled aggregate with different proportions was obtained by considering the effect of load as follows:

$$
K=0.00239 \times a+0.8804 R^{2}=0.97
$$

where $a$ is the proportion of recycled aggregate, \%; $K$ is the proportional coefficient of settlement, dimensionless.

It can be seen from Equation 5 that the value of $K$ is only related to the mix proportion and not the load because the ratio of the settlement inherently contains the load.
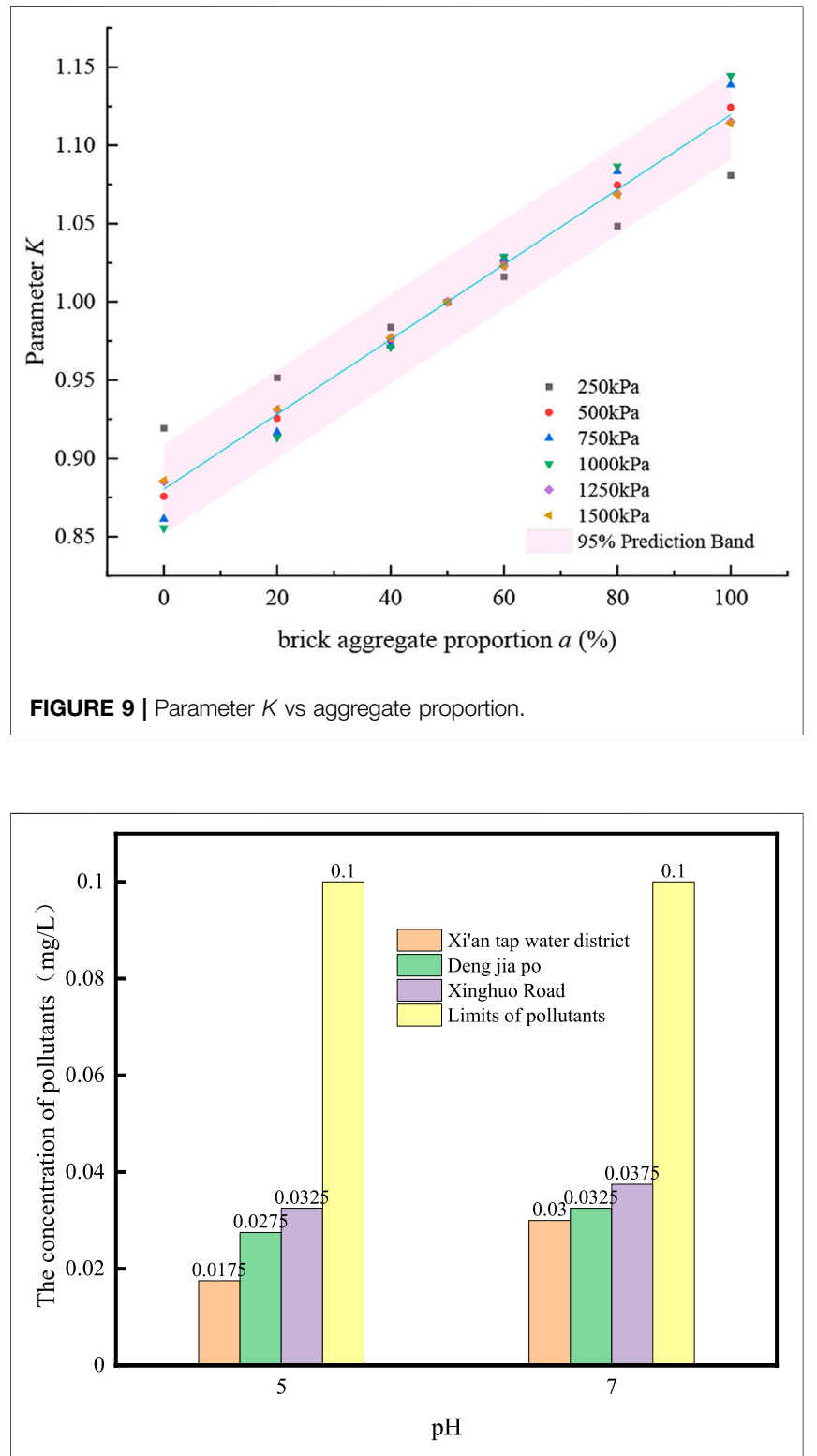

FIGURE 10 | Standard leaching results of $\mathrm{Cr}$ from recycled aggregate.

By combining Equations 4, 5, the prediction formulas for the settlement of recycled aggregate with different proportions under different moisture contents and different loads can be obtained as follows:

$$
\begin{aligned}
& s=K\left(-0.068 w^{2}+1.501 w+0.035 P-5.559\right) \\
& K=0.0239 \times a+0.8804
\end{aligned}
$$

where $a$ is the proportion of recycled aggregate, $\%$; $K$ is a proportional coefficient of settlement, dimensionless; $w$ is the moisture content of recycled aggregate, $\%$; $p$ is the load on the recycled aggregate, $\mathrm{kPa} ; s$ is the settlement of recycled aggregate, $\mathrm{mm}$.

Finally, the influence of the number of dry-wet cycles on the settlement of recycled aggregate was considered. When 


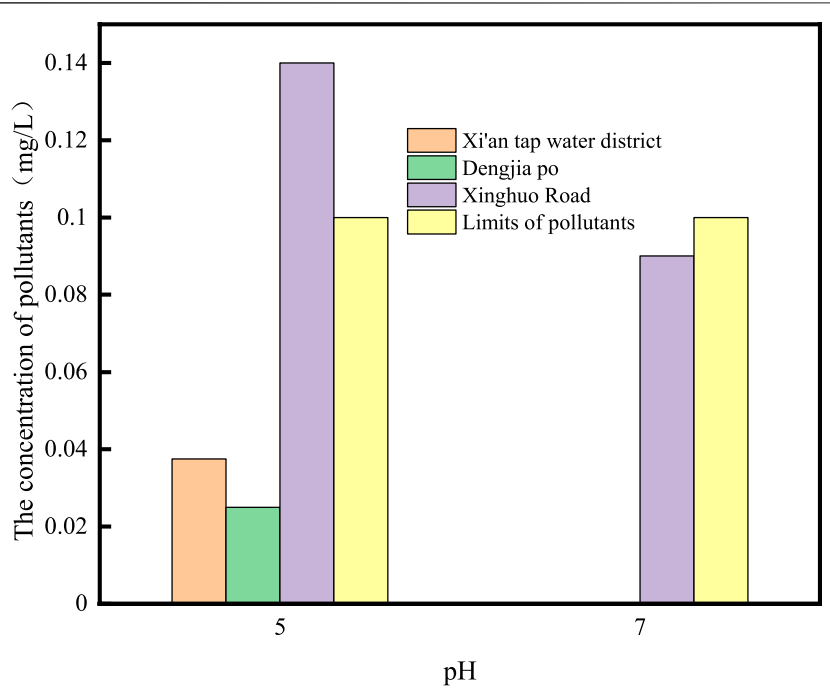

FIGURE 11 | Enhanced leaching test results of Cr from recycled aggregate.

recycled aggregate is used in storage and recycling facilities, the number of dry-wet cycles of aggregate is a long-term factor that may affect the final settlement of a structure. As mentioned earlier, the compressive settlement of recycled aggregate may increase by $14.9-17.5 \%$ during long-term drywet cycles. This means that aggregate settlement will increase during long-term cycles, but it will not exceed $20 \%$; therefore, based on Equation 6, a safety reserve parameter $F$ was added to characterize the influence of the number of dry-wet cycles on aggregate compression settlement. Its value is 1.20 , and Equation 7 was obtained to predict the final settlement of recycled aggregate with different proportions under different moisture contents, loads, and dry-wet cycles.

$$
\begin{aligned}
& s=1.2 \times K\left(-0.068 w^{2}+1.501 w+0.035 P-5.559\right) \\
& K=0.0239 \times a+0.8804
\end{aligned}
$$

\section{Environmental Impact of Recycled Aggregate}

$\mathrm{Cr}$ is the only pollutant in recycled aggregate obtained from the three selected sites. The standard leaching test results showed that the pollutant concentrations at the three locations were all lower than the standard requirements ( $\mathrm{Li}$ et al., 2020).

The enhanced leaching test results showed that the pollutant concentration of recycled aggregate obtained from Xinghuo Road was higher than the standard value, which shows that the source of recycled aggregate should be investigated to avoid possible environmental risks.

\section{CONCLUSION}

In this paper, the feasibility of using the recycled aggregate from construction waste as a filling material for sponge city storage and recycling facilities was discussed using large-scale indoor compression tests and leaching tests. The main conclusions are as follows:

(1) The influence of moisture content, ratio, and the dry-wet cycles of the recycled aggregate of construction waste on its compression settlement was analyzed. Upon increasing the aggregate moisture content, settlement first increased and then decreased, and an extreme point was reached near the optimal moisture content. Upon increasing the load, aggregate settlement increased but at an increasingly slower rate. Upon increasing the brick aggregate proportion, the settlement of mixed aggregate increased. Upon increasing the number of dry-wet cycles, aggregate settlement increased, but at an increasingly slower rate.

(2) The crushing characteristics of recycled aggregate were consistent with the settlement variation characteristics. It shows that aggregate crushing was the main reason for the settlement deformation of structures built from recycled aggregate.

(3) Recycled aggregate may have certain environmental risks due to $\mathrm{Cr}$ leaching. When applying recycled aggregate, the sources of such contaminants should be investigated to prevent environmental pollution.

(4) The results of indoor compression test results were used to establish a formula to predict the settlement of recycled aggregate used for filling storage and recycling facilities in a sponge city. This formula was only based on the experimental results of this paper, and its broader applicability needs to be tested in practice.

\section{DATA AVAILABILITY STATEMENT}

The original contributions presented in the study are included in the article/Supplementary Material, further inquiries can be directed to the corresponding author.

\section{AUTHOR CONTRIBUTIONS}

All authors listed have made a substantial, direct, and intellectual contribution to the work and approved it for publication.

\section{FUNDING}

This research was supported by the Fundamental Research Funds for the Central Universities, CHD(300102260507)and the Fundamental Research Funds of Power China Northwest Survey, Design and Research Institute Co., Ltd. (XBY2017-KJ-15). 


\section{REFERENCES}

Bendixen, M., Best, J., Hackney, C., and Iversen, L. L. (2019). Time Is Running Out for Sand. Nature 571 (7763), 29-31. doi:10.1038/d41586-019-02042-4

Chang, X. (2017). Prediction And Analysis of Settlement Law of Subgrade Section Filled with Construction Waste. Master, Xi'an: Chang'an University

Chen, D., Wang, S., Shen, M., Qian, Q., and Birhane, T. G. (2020). Aggregate Micro Tribological Properties of Sponge City Permeable Pavement Base Layer under Vehicle Loading. Construction Building Mater. 261, 120424. doi:10.1016/ j.conbuildmat.2020.120424

Chen, H. (2004). Experimental Study on Compaction of Coarse Grained Soil. Xi'an: Chang'an University

CN-GB (2019). Standard for Geotechnical Testing Methods. (Beijing: China Planning Press

Einav, I. (2007). Breakage Mechanics-Part II: Modelling Granular Materials. J. Mech. Phys. Sol. 55 (6), 1298-1320. doi:10.1016/j.jmps.2006.11.004

Galvín, A. P., Ayuso, J., Jiménez, J. R., and Agrela, F. (2012). Comparison of Batch Leaching Tests and Influence of $\mathrm{pH}$ on the Release of Metals from Construction and Demolition Wastes. Waste Manage. 32 (1), 88-95. doi:10.1016/ j.wasman.2011.09.010

Hansen, T. C. (1992). Recycling of Demolished concrete and Masonry. Los Angeles: CRC Press.

Hardin, B. (1985). Crushing of Soil Particles. J. Geotechnical Eng. 111 (1985), 10-1177. doi:10.1061/(asce)0733-9410(1985)111:10(1177)

Hong, X. (2016). Analysis on Settlement Characteristics of Embankment Filled with Construction Waste. Master, Xi'an: Chang'an University

Kong, X., Wang, L., and Chen, G. (2020). Ecological Resilience Restoration in the Watershed of the Hancang River. Oje 10 (10), 651-663. doi:10.4236/ oje. 2020.1010040

Kong, Y., Xu, M., and Song, E. (2017). An Elastic-Viscoplastic Double-YieldSurface Model for Coarse-Grained Soils Considering Particle Breakage. Comput. Geotechnics 85, 59-70. doi:10.1016/j.compgeo.2016.12.014

Lee, C.-H., Du, J.-C., and Shen, D.-H. (2012). Evaluation of Pre-coated Recycled concrete Aggregate for Hot Mix Asphalt. Construction Building Mater. 28 (1), 66-71. doi:10.1016/j.conbuildmat.2011.08.025

Li, L., Liu, J., Henglin, X., Yaoyao, P., and Xu, W. (2020). Research on Environmental Impact of Heavy Metal Leaching from Construction and Demolition Waste Aggregate. Journal of Yangtze River Scientific Research Institute, 1-7.

Limbachiya, M. C., Leelawat, T., and Dhir, R. K. (2000). Use of Recycled concrete Aggregate in High-Strength concrete. Mat. Struct. 33 (9), 574-580. doi:10.1007/ bf02480538

Lopez Meza, S., Garrabrants, A. C., van der Sloot, H., and Kosson, D. S. (2008). Comparison of the Release of Constituents from Granular Materials under Batch and Column Testing. Waste Manage. 28 (10), 1853-1867. doi:10.1016/ j.wasman.2007.11.009

López-Gayarre, F., Serna, P., Domingo-Cabo, A., Serrano-López, M. A., and LópezColina, C. (2009). Influence of Recycled Aggregate Quality and Proportioning Criteria on Recycled concrete Properties. Waste Manage. 29 (12), 3022-3028. doi:10.1016/j.wasman.2009.07.010

Ma, J., Sun, D., Pang, Q., Sun, G., Hu, M., and Lu, T. (2019). Potential of Recycled concrete Aggregate Pretreated with Waste Cooking Oil Residue for Hot Mix Asphalt. J. Clean. Prod. 221, 469-479. doi:10.1016/j.jclepro.2019.02.256

Meza, S. L., van der Sloot, H., and Kosson, D. S. (2009). The Effects of Intermittent Unsaturated Wetting on the Release of Constituents from Construction Demolition Debris. Environ. Eng. Sci. 26, 463-469. doi:10.1089/ees.2007.0337
Nakaoka, T., Mochizuki, A., and Sakaguchi, O. (1994). EVALUATION OF DENSITY FROM COMPACTION TESTS ON COARSE GRAINED SOILS. Doboku Gakkai Ronbunshu 1994, 177-185. doi:10.2208/ jscej.1994.499_177

Saeed, A.. (2008). Performance-related Tests of Recycled Aggregates for Use in Unbound Pavement Layers.doi:10.17226/23108

Shen, W., Liu, Y., Wu, M., Zhang, D., Du, X., Zhao, D., et al. (2020). Ecological Carbonated Steel Slag Pervious concrete Prepared as a Key Material of Sponge City. J. Clean. Prod. 256, 120244. doi:10.1016/j.jclepro.2020.120244

Tang, Y., Feng, W., Chen, Z., Nong, Y., Yao, M., and Liu, J. (2021a). Experimental and Theoretical Investigation on the Thermo-Mechanical Properties of Recycled Aggregate Concrete Containing Recycled Rubber. Front. Mater. 8, 655097. doi:10.3389/fmats.2021.655097

Tang, Y., Feng, W., Feng, W., Chen, J., Bao, D., and Li, L. (2021b). Compressive Properties of Rubber-Modified Recycled Aggregate concrete Subjected to Elevated Temperatures. Construction Building Mater. 268, 121181. doi:10.1016/j.conbuildmat.2020.121181

Wang, J., Zhang, P., Yang, L., and Huang, T. (2015). Adsorption Characteristics of Construction Waste for Heavy Metals from Urban Stormwater Runoff. Chin. J. Chem. Eng. 23 (9), 1542-1550. doi:10.1016/ j.cjche.2015.06.009

Yang, S., and Lee, H. (2017a). Freeze-Thaw Resistance and Drying Shrinkage of Recycled Aggregate Concrete Proportioned by the Modified Equivalent Mortar Volume Method. Int. J. Concr Struct. Mater. 11, 617-626. doi:10.1007/s40069017-0216-5

Yang, S., and Lee, H. (2017b). Mechanical Properties of Recycled Aggregate concrete Proportioned with Modified Equivalent Mortar Volume Method for Paving Applications. Construction Building Mater. 136, 9-17. doi:10.1016/j.conbuildmat.2017.01.029

Yang, X., Zhu, Y., and Guo, N. (2017). Strength and Deformation Characteristic of Soil-Rock Mixture and Settlement Prediction in High Filled Prodects. Chin. J. Rock Mech. Eng. 36 (7), 1780-1790.

Yt, A., Shu, F. B., Jc, B., Lm, B., Ll, B., and Xw, C. (2020). Axial Compression Behavior of recycled-aggregate-concrete-filled GFRP-Steel Composite Tube Columns. Eng. Structures 216, 110676. doi:10.1016/j.engstruct.2020.110676

Yuan, X., Tang, Y., Li, Y., Wang, Q., Zuo, J., and Song, Z. (2018). Environmental and Economic Impacts Assessment of concrete Pavement brick and Permeable brick Production Process - A Case Study in China. J. Clean. Prod. 171, 198-208. doi:10.1016/j.jclepro.2017.10.037

Conflict of Interest: The authors declare that the research was conducted in the absence of any commercial or financial relationships that could be construed as a potential conflict of interest.

Publisher's Note: All claims expressed in this article are solely those of the authors and do not necessarily represent those of their affiliated organizations, or those of the publisher, the editors and the reviewers. Any product that may be evaluated in this article, or claim that may be made by its manufacturer, is not guaranteed or endorsed by the publisher.

Copyright (c) 2021 Xuetong and Debin. This is an open-access article distributed under the terms of the Creative Commons Attribution License (CC BY). The use, distribution or reproduction in other forums is permitted, provided the original author(s) and the copyright owner(s) are credited and that the original publication in this journal is cited, in accordance with accepted academic practice. No use, distribution or reproduction is permitted which does not comply with these terms. 